\title{
Genetic and non-genetic factors influencing Ostertagia ostertagi antibodies in UK Holstein Friesian cattle
}

C Hayhurst $^{1}$, A Bradley ${ }^{2}$, K Hunter $^{1}$, A B Forbes ${ }^{3}$, M D Royal ${ }^{1}$

${ }^{1}$ University of Liverpool, Liverpool, United Kingdom, ${ }^{2}$ Quality Milk Management Services Ltd, Somerset, United Kingdom, ${ }^{3}$ Merial, Lyon, France

Email: mdroyal@liverpool.ac.uk

Introduction Today's Holstein-Friesian dairy cattle selection indices are much broader than their predecessors; however there are still areas, concerning health and welfare that require investigation. Sub-clinical gastrointestinal (GI) nematode infections are one such area, $\mathrm{O}$. ostertagi $(\mathrm{Oo})$ being one of the most widespread and important GI nematode parasites of cattle in temperate regions. It is known to cause severe clinical disease in young cattle and causes reduced yield, weight and body condition score in adults. Although sheep have been selected for resistance and/or resilience to nematode infection, knowledge of protective immune responses in cattle and thus genetic selection opportunities to date are limited. The predominant immunoglobulin involved in the humoral immune response to GI nematodes is IgG (Sanchez et al., 2004b). In sheep, IgA is considered to regulate $O$. circumcincta worm fecundity (Stear et al., 1996) but it has been rarely studied in cattle and is barely detectable in serum or milk, thus its role is unresolved. However, total IgG levels in serum have been related to acquired and protective immunity to Oo in cattle (Kloosterman et al., 1984). The aim of this work was to estimate the genetic variation, heritability and effects of other non-genetic factors on Oo specific total IgG concentration in milk of Holstein Friesian cattle.

Materials and methods Anti- $O o$ antibody level (total $\mathrm{IgG}_{1}$ and $\mathrm{G}_{2}$ ) was determined by a solid-phase indirect enzyme linked immunosorbent assay kit (ELISA; Charlier et al., 2005) and measured using optical density ratio $\left(\mathrm{ODR}=\mathrm{OD}_{\text {sample }}-\right.$ $\mathrm{OD}_{\text {negative control }} / \mathrm{OD}_{\text {positive control }}-\mathrm{OD}_{\text {negative control }}$ ) from milk samples collected from 1,303 Holstein-Friesian cattle in 255 commercial dairy farms between 2002 and 2004 during their first (82\%) and other (2-12) lactations. Various fixed, random and nested effects (herd, area of country, year, month and season of sample, time of sample, parity and days postpartum) were systematically investigated in the model. The final model included the fixed effects of herd $(\mathrm{n}=229)$, season of sample $(n=4)$ and the random effect of sire of animal $(n=461$; mean \pm standard deviation; $2.76 \pm 2.99$ daughters per sire, range 1 to 27). Analysis of the data with a full animal model was not possible due to data limitations (lack of dam identification and some sire pedigree information). Thus, only the most simple sire model fitted to the ODR data using ASREML software and variance components estimated. Caution must therefore be used when interpreting the variance component estimates in terms of reduced accuracy and potential bias.

Results The association with days postpartum, area of country, parity, sample time (AM or PM), sample month and year on ODR were not significant and therefore were not included in the final univariate model. Season had a significant $(\mathrm{P}<0.0001)$ effect with ODR largest during summer months (June to August) and lowest in winter (December to February). This pattern is thought to reflect the ingestion of infective larvae, which are present on pasture and whose concentrations typically increase throughout the grazing season. Antibody levels typically decline during housing over winter because of the cessation of larval ingestion. ODR was heritable and the estimate was significantly different from zero $\left(0.13 \pm 0.12 ; \mathrm{h}^{2}\right.$ \pm s.e.; $\mathrm{P}<0.05$ ). This is comparable to estimates of antibody response to other conditions in serum (Wagter et al, 2000; Gonda et al., 2006). Furthermore, the present study confirms the significant effects of sire and herd on Oo antibody level also found in a smaller study ( $\mathrm{n}=9$ sires) using pooled milk samples per sire in New Zealand dairy cattle (Morris et al., 2002).

Conclusion This study found that anti-Oo total IgG antibody response is under genetic control and highlights the significant effect of season of sample and herd. These sources of environmental variation would need to be considered in future investigations into the potential use of antibody response in genetic selection and also in parasite control programs. The possibility of anthelmintic resistance may mean that in the future, producers may use a combination of management and genetic selection to control parasitic infection and susceptibility. Because of the relatively small dataset available and the very simplified genetic model applied, further large scale genetic studies need to be carried out to fully dissect the relationship between parasitic susceptibility and antibody response and the genetic and non-genetic factors affecting them.

Acknowledgements The authors are grateful to BSAS/Genesis Faraday for a vacation scholarship and Merial for their funding.

\section{References}

Charlier, J., E. Claerebout, E.De. Muelenaere, and J. Vercruysse. 2005. Veterinary Parasitology 133, 91-100.

Gonda, M.G., Y.M. Chang, G.E. Shook, M.T. Collins, and B.W. Kirkpatrick. 2006. Journal of Dairy Science 89, $1804-12$

Kloosterman, A., G.A.A. Albers, and R. Van den Brink. 1984. Veterinary Parasitology 15, 135-150

Morris, C.A., N.G. Cullen, R.S. Green, and S.M. Hickey. 2002. New Zealand Journal of Agricultural Research 45, 179-185

Sanchez, J., F. Markham, I. Dohoo, J. Sheppard, G. Keefe, and K. Leslie. 2004b. Veterinary Parasitology 120, 319-330

Wagter, L.C., B.A. Mallard, B.N. Wilkie, K.E. Leslie, P.J. Boettcher, and J.C. Dekkers. 2000. Journal of Dairy Science 83, 488-98 